University of Nebraska - Lincoln

DigitalCommons@University of Nebraska - Lincoln

To Improve the Academy

Professional and Organizational Development

Network in Higher Education

1996

\title{
A Department-Based Approach to Developing Teaching Portfolios: Perspectives for Faculty Developers
}

Milton D. Cox

Follow this and additional works at: https://digitalcommons.unl.edu/podimproveacad

Part of the Higher Education Administration Commons

Cox, Milton D., "A Department-Based Approach to Developing Teaching Portfolios: Perspectives for Faculty Developers" (1996). To Improve the Academy. 354.

https://digitalcommons.unl.edu/podimproveacad/354

This Article is brought to you for free and open access by the Professional and Organizational Development Network in Higher Education at DigitalCommons@University of Nebraska - Lincoln. It has been accepted for inclusion in To Improve the Academy by an authorized administrator of DigitalCommons@University of Nebraska - Lincoln. 
Cox, M.D. (1996). A department-based approach to developing teaching portfolios: Perspectives for faculty developers. In L. Richlin (Ed.), To Improve the Academy, Vol. 15 (pp. 275-302). Stillwater, OK: New Forums Press and the Professional and Organizational Development Network in Higher Education. Key words: Department, Faculty Development, Faculty Development Programs, Faculty Development Role, Portfolios.

\section{A Department-Based}

\section{Approach to Developing Teaching Portfolios: Perspectives for Faculty Developers}

\section{Milton D. Cox}

Miami University

The Department-Based Teaching Portfolio Project, now in its third year at Miami University, provides departments the flexibility to design and implement teaching development processes that honor the diversity of disciplines, departmental cultures, and leadership styles of department project coordinators. This approach has generated an interesting variety of departmental processes and results, for example, in the use of off-campus consultants and in the manner in which teaching portfolios are developed. Based upon the outcomes of the Project, 20 recommendations inform faculty developers in their roles as department developers. 


\section{Department-Based vs. Campus-Wide}

Although departments play the most important role in shaping the curriculum, offering courses, enabling student learning, and determining faculty rewards (Cerbin, 1994; Murray, 1995), there have been few broad, department-based approaches to developing teaching. Faculty development efforts to enhance departmental teaching cultures have focused on working with department chairs (Boice, 1985; Hilsen \& Rutherford, 1991; Sorcinelli \& Aitken, 1995; Wilhite, 1990). In Wright and O'Neil's (1995) survey of U.S. faculty development specialists asking respondents to rate 36 teaching improvement practices according to their confidence in the practice's potential to improve the quality of teaching, the second-, third-, and fifth-ranked items involved the role of deans and department chairs. Yet, department-based teaching development projects or initiatives were not among the 36 teaching improvement practices. Similarly, when Kurfiss and Boice (1990) surveyed POD members to determine existing and desired faculty development practices, they found that only 16 percent (23rd out of 26 faculty development practices) were involved with training chairs to facilitate teaching, while 60 percent (ranked first) planned or desired to institute that practice. Again, department-based teaching projects or similar activities were not included in the list.

Within the last five years, a few universities have initiated department-based efforts at developing teaching. For example, the University of Nebraska-Lincoln initiated a department-based project to improve teaching by rewarding teaching (Lunde \& Barrett, 1996). Most departments in the project employ some version of portfolio evaluation, and an annual award of $\$ 25,000$ is given within the University of Nebraska four-campus system to the department that demonstrates excellence in teaching. The Ohio State University has just instituted a similar award. Walvoord (1994) and colleagues at the University of Cincinnati have formulated and used 12 questions that departments can ask to determine their teaching and learning cultures. A department-based project is in its third year at Eastern Michigan University (DeZure, 1996); this project involves departmental instructional liaisons-faculty members, not department chairs-who re- 
ceive one-quarter release time for one or two semesters to provide leadership and support for instructional development within their departments. The liaison conducts a departmental needs assessment, identifies goals and activities, networks with other liaisons across department lines, and arranges departmental programs on teaching issues.

Nationally, department-based projects are being tried across universities. One example is the peer review of teaching project of the American Association for Higher Education (AAHE), in which selected departments in the same disciplines at 12 universities are investigating and establishing ways to initiate and improve the peer review of teaching (Hutchings, 1996).

On most campuses the approach to introducing and initially developing teaching portfolios has been campus-wide: The teaching center or instructional improvement committee has conducted workshops for faculty to learn about and perhaps work individually with outside or teaching center consultants to build personal portfolios (e.g., Eison, 1994). The focus has been on individual faculty, not departments. Seldin's (1993) report on the use of teaching portfolios at nine institutions indicated that only the University of Nebraska-Lincoln (UN-L) involved departments initially. Anderson's (1993) 25 profiles of campus use of teaching portfolios revealed that besides UN-L, only the University of Colorado at Boulder was taking a department-based approach, working with one department at a time. Another example of a campus-wide approach at a major research university is described by Davis and Swift (1995), who reported the results of a survey of faculty and department chair reactions to teaching portfolios.

A combination of campus-wide and department-based approaches to teaching portfolio development is illustrated by the Teaching Improvement Program competition, initiated by the University of Florida in 1993 (Ross, Barfield, Campbell, Capaldi, \& Lombardi, 1995). Funded by a grant from the state legislature, the program seeks to enhance teaching by using teaching portfolios to identify excellent instructors. This teaching portfolio development process is initiated outside departments, is motivated by a substantial grant to the university, requires that initial portfolios be developed in a short time, is used 
for evaluation for awards, begins with general university-wide guidelines followed by departments localizing these guidelines, involves college- and university-wide committees and administrators in the final evaluation process, and results in revised guidelines at the university level.

The initial campus-wide rather than departmental focus is noteworthy because when departments consider change with respect to scholarship or curriculum, they usually consult their disciplinary professional organizations and colleagues in the same discipline at other institutions. However, this has not often been the case when it comes to change with respect to teaching. In most university departments, the balance between teaching and scholarship (resources, rewards, prestige) has not favored teaching during the last 30 years. Hence, the development and evaluation of teaching have had a campus-wide focus. Because department cultures have been difficult to change from the outside, a strategy adopted by faculty developers has been to provide campus-wide programs for individual faculty who may then carry back new attitudes and skills to their departments; the plan is that in time, a critical mass of "reformers" will change departmental attitudes and procedures.

Departments and disciplines have different cultures and are where academic lives are lived and where faculty rewards are determined. The crucial role of departments and portfolios in enhancing teaching and learning and in transforming academic culture motivated Miami University to design a department-based approach to developing teaching portfolios. Miami initiated a flexible development process, focused entirely on departments, free of university-wide guidelines, with chair support but guided by a project coordinator (usually not the chair), and providing necessary time for departments to investigate, design, experiment with, and then adopt, modify, or reject a teaching portfolio approach to enhancing and evaluating teaching and learning.

\section{A Department-Based Approach}

\section{Context}

Miami University is a Doctoral I (Carnegie classification) institu- 
tion with 16,445 students, 873 full-time faculty, 45 academic departments, six academic divisions, and two regional campuses. There are several university-wide opportunities for faculty to discuss teaching in small groups across disciplines and campuses. For example, there are a year-long junior faculty program, a similar program for senior faculty, and seminars sponsored by groups such as the Liberal Education Council and the University Honors Program. There are also over a dozen types of teaching grants that support the teaching innovations and initiatives of individual faculty. However, until 1992, only one teaching grant program supported departments as a whole in developing and completing department-wide teaching projects, and only two or three such grants were awarded each year from a pool of $\$ 12,000$ to $\$ 25,000$. Thus, the department-based approach to developing teaching portfolios was designed to encourage a dialogue about teaching inside departments, to foster collaboration and collective responsibility within departments, to incorporate a departmental support base of faculty who had been active in the campus-wide programs, and to provide a new source of teaching development funds for departments. Initiated in 1993, the program was named the Teaching Portfolio Project

All campus publicity about the Project emphasizes that it is a grassroots effort, started by faculty and sponsored by Miami's Committee on the Improvement of Instruction (CII); is made up of volunteers from departments and carried out in the spirit of collaboration and experimentation; is not motivated by or subject to any administrative or hidden agendas; is long-term and will be challenging because it involves substantial change for individuals and departments.

\section{Objectives}

The long-term teaching and learning objectives of the Project are to enable departments to:

1. improve their evaluation-of-teaching systems;

2. increase the dialogue about teaching and learning within the department;

3. provide more evidence about how teaching affects learning;

4. investigate and select multiple ways of evaluating teaching; 
5. incorporate into evaluation the complex, multidimensional nature of teaching and learning;

6. enhance the importance of and rewards for teaching;

7. provide a record and legacy of teaching to be used in planning, celebration, and review; and

8. communicate about innovative and effective teaching and improved learning to the university, to programs in the same disciplines at other universities, to parents, to legislators, and to the public.

\section{Selection of Departments}

The University Director for Teaching Effectiveness Programs at Miami University designed the Project in consultation with CII. Composed of faculty and student members, CII selects participating departments, and the Director coordinates the Project. To encourage applications and participation, each department in the Project receives a grant of $\$ 5,000$ to be used for Project-related costs. Part of the grant may be reserved for a department Project coordinator who is extensively involved in the Project. Funds may cover release time, professional expenses, etc., but cannot be used as salary. To keep options open, departments do not have to specify the use of grant funds in advance or to adhere to rigid timelines. For the first two years, funds totaling $\$ 35,000$ each year were supplied by Miami's Lilly Conference on College Teaching or reallocated from other teaching development grants to provide the $\$ 5,000$ teaching portfolio grants to 14 units. Because developing teaching portfolios as part of an improved evaluation-of-teaching system takes more than one year, departments can carry over funds from the initial grant to subsequent years. New additional-year funding is also available for departments that make progress and demonstrate need; applications from such departments are judged in competition with first- and additional-year applications from other departments.

In the request for proposals, CII acknowledges that ways of investigating and implementing an evaluation-of-teaching system will vary from department to department; therefore, no guidelines are imposed on the investigation or on the type of system to be developed. 
Departments are informed of and given access to the literature on teaching portfolios, and new applicants are invited to consult with experienced Miami Project coordinators or with departments in the same discipline at other universities.

For a department applying for the first time, the grant proposal is limited to four pages and requires the following information, along with letters of support from the department chair and divisional dean:

1. A brief indication of the department's current process for evaluating teaching.

2. The extent to which the proposed approach is already in place or in the planning or investigation stages.

3. The extent of consultation already undertaken with departments at other universities and with departments in the Miami Teaching Portfolio Project.

4. Name of the department's Project coordinator and his or her qualifications for coordinating this Project.

5. The names of and information about the Project team members and why they were selected (subdisciplines, years at Miami, promotion and tenure committee membership, etc.).

6. Evidence of the department's interest in and commitment to the Project (the letter from the chair is important here).

7. The proposed approach for implementing the Project, including as many details as possible (although the selection committee realizes that, at this point, there may be several avenues to explore).

8. A conjecture about the department's willingness to eventually adopt the proposed approach.

9. Timeline for the first year of the Project (and, if appropriate, the second year).

10. Plans for and progress toward establishing a monthly departmental teaching colloquium series.

The application for new funding for an additional year consists of teaching portfolios developed during the previous year(s), a year-end progress report, letters of commitment from the chair and the dean, and a two-page proposal stating:

1. Department goals, objectives, and plans for the next year, including the names of faculty on the current team who will continue to 
participate, the names of department members who are joining the team, and plans for mentoring new members.

2. Timeline for the upcoming year.

3. A line-item budget and an explanation of how the funds will be used (including unexpended funds from the current year).

The selection criteria for first- or additional-year participation in the Project include potential impact upon teaching and learning and their evaluation, the department's interest in and commitment to the Project, qualifications of the coordinator, broad representation of the team, and potential for success of the Project.

Proposals for initial participation are accepted twice each year: on November 1 during the first semester, and in May, two weeks after the end of the second semester. Proposals for additional-year funding are also received in May.

\section{The Portfolio Development Process}

The Project's request for proposals contains the following scenario as an example of department teaching portfolio development. Most departments have followed this model.

The department chooses a coordinator and a Project team. The coordinator is a department member who is well respected, particularly in the area of teaching. The team includes broad membership: some from the department's promotion and tenure committee; junior, mid-career, and senior faculty; and representatives from subdisciplines of the department. In addition to creating initiatives and coordinating activities in the department, the coordinator is expected to meet monthly in a seminar with the coordinators from the other participating departments to share strategies, problems, and progress. The Director chairs the coordinators group and serves as consultant.

The department coordinator and the Project team first investigate the literature, the experiences of other Miami departments involved in the Project, and the experiences of departments in the same discipline at other universities. The coordinator and the Project team then decide upon a plan to develop and to present to the department.

With departmental approval, the plan is piloted by the Project team.

The pilot Project is evaluated by the team, then by the department. If necessary, the plan is revised. This process may be repeated. 
If the department finds value in the approach, it is adopted and tried by all faculty in the department. The approach will be revised as the department attempts to define and measure effective teaching and learning.

After reading the literature on portfolios, each department designs and initiates its own development process; no expert is brought to campus for a university-wide presentation or consultation. However, in November 1993, four months after the Project began, the national Lilly Conference on College Teaching held at Miami provided an opportunity for the initial Project coordinators and teams to attend nine sessions about portfolios; national interest in teaching portfolios was high, and a rich variety of portfolio topics were volunteered for the Conference. A panel of all the Conference presenters who were leading sessions on portfolios offered a helpful overview. (Videotapes and handouts for most of the nine presentations are available from the author.) The Miami participants feasted at this buffet and refined their portfolio tastes. Some used the opportunity to interview and select consultants to work with their departments.

Miami Project coordinators meet monthly over dinner to discuss their departments' plans and progress, to share successes and failures, to seek and offer support, to examine portfolio drafts, and to plan seminars to share experiences with colleagues on campus and with colleagues from other campuses who attend the Lilly Conference. Although new members have joined the group each semester, the group has matured developmentally over three years. During the first year, the monthly meetings primarily involved seeking answers and reporting progress. In the second year, seven new members were welcomed, portfolios constructed by first-year participants became available to read and discuss, and the group broadened the dialogue about teaching. The third year saw the group beginning to look for patterns in the various portfolios, to study the evaluation of these portfolios, to prepare and discuss cases about teaching, and to consider other issues in higher education. This development in the coordinators group has been mirrored by some of the departments now in their second and third years of the Project. 


\section{The Project Participants}

\section{Departments and Units}

During the first three years of the Teaching Portfolio Project, 1993-94 through 1995-96, 11 of Miami's 45 departments have participated directly. In addition, five nondepartmental units have joined in: two of the four professional schools (participating as divisions), the School of Interdisciplinary Studies, one of two regional campuses, and the University Libraries. When the participating departments in the two professional schools are also counted, 19 departments-almost half of those in the university - have been involved. Table 1 lists these units with their initial year of participation.

The CII selection committee approved the participation of the professional schools because their Project coordinators were experienced leaders, were active participants in campus-wide teaching development programs, and proposed to involve half or all of their school's departments. The selection committee realized that schoolwide participation might result in a lack of ownership and commitment at the department level but decided to approve the participation of the two schools. The risk apparently was justified, because one of the school's departments has now adopted teaching portfolios for the evaluation of teaching for promotion, tenure, and merit pay decisions. Because the School of Interdisciplinary Studies has no individual departments, it fit exactly into the Project's department strategy. Both regional campuses are urban, nonresidential, two-year campuses with classes different from the residential main campus; however, faculty on the regional campuses obtain tenure through their departments on the main campus. The CII selection committee approved the participation of the regional campus to foster its special teaching culture as well as the effect it might have on the departments of the participants. The University Libraries proposed a broad study of their instructional roles and ways to evaluate them; the absence of literature and the clear need in this area (Hutchings, 1993, p. 17) convinced the CII selection committee to include the Libraries. 


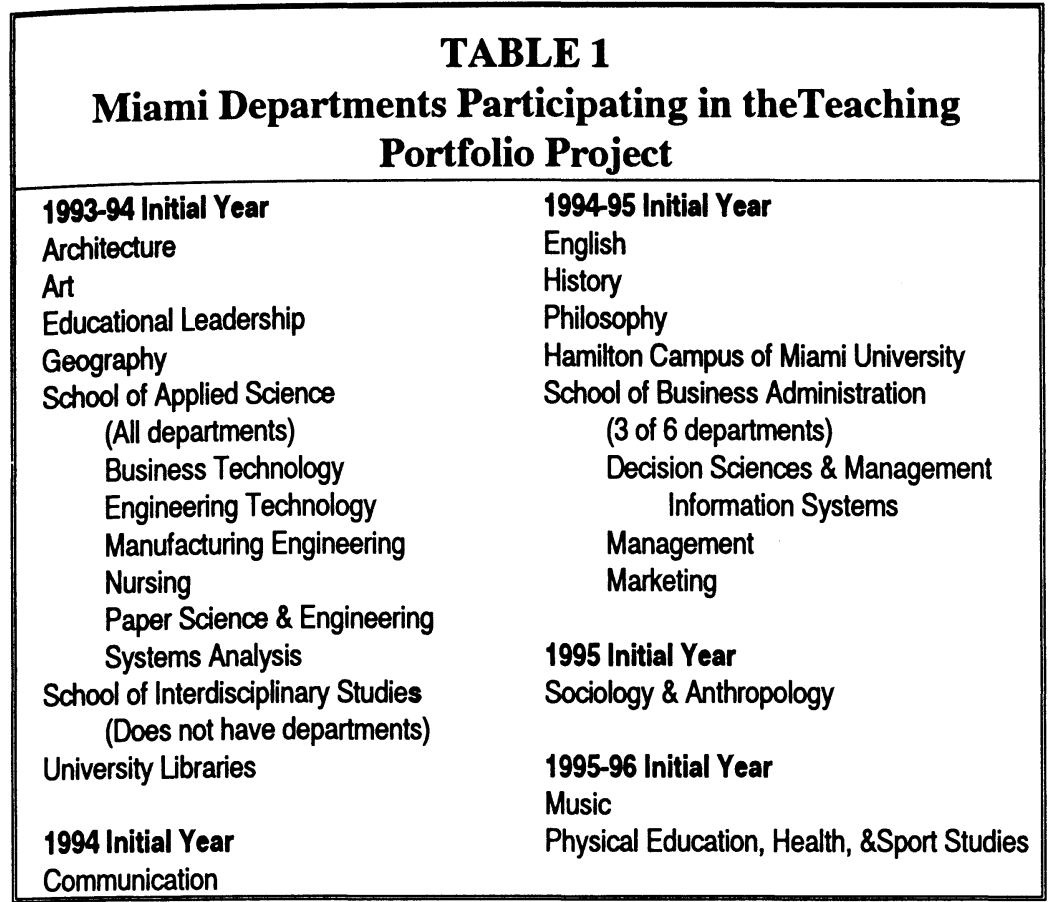

Ten departments in the Project report that the primary reason they decided to participate was to improve the evaluation of teaching; five participated to increase departmental dialogue about teaching, and four to connect with existing student portfolio activities. Other reasons for participation mentioned were to improve teaching effectiveness in the department, to reinvigorate teaching in the department, to expand upon the course portfolios already required for accreditation, to improve curricular interconnections, and to investigate the effect of portfolios on teaching.

\section{Department Project Coordinators}

Richlin and Manning (1995) recommend that department chairs play a behind-the-scenes role in portfolio development and evaluation. In the Miami culture, most chairs have so many commitments that requiring them to play an active role in the Project might result in a chair's deciding that the department not participate at all. Thus, Project 
leadership comes from a faculty member in the department. Miami's approach to developing teaching portfolios within departments has been to engage the entrepreneurial spirit of a department coordinator who is enthusiastic about and experienced in teaching and learning. The interest, commitment, and leadership abilities of the department Project coordinator are essential to success. Faculty developers and department chairs considering a department-based teaching development project should look for the qualities below to help attract, identify, and select coordinators.

Of the $\mathbf{2 3}$ faculty members who have served as coordinators, 19 have previously been participants in one or two of the year-long Miami teaching development programs: the Teaching Scholars Program for junior faculty, in place for 16 years (Cox, 1994), and the Senior Faculty Program for Teaching Excellence, in place for five years (Cox \& Blaisdell, 1995). Seven of the coordinators have been in the Teaching Scholars Program, and eight in the Senior Faculty Program for Teaching Excellence; 10 have served as senior faculty mentors in the Teaching Scholars Program. The interest and experience of these coordinators is evidence of the commitment to teaching and community that long-term faculty development programs can generate (Cox, 1995b). Faculty members report several reasons for their initial interest in coordinating the Project, but mentioned most often is the interest in portfolios generated during previous participation in a Miami teaching development program.

Three coordinators volunteered because of their interest in the evaluation of teaching. Two were interested because teaching is their research area; two wished to improve their teaching; two sought the opportunity for self-reflection; and two wanted to lead teaching improvement activities. Two also stepped forward because of their interest in mentoring junior faculty. One coordinator was motivated to volunteer by hearing a national expert at a conference, whereas the teaching portfolio appealed to another's interest in team teaching and helping those teaching common courses see common goals. Finally, one coordinator wrote, "I am interested in continuous quality improvement which often focuses on assessment of key processes and performance. Teaching is one of our department's key processes that we seek to continuously improve." Only three departments chose co-co- 
ordinators, and four units changed coordinators during the Project (two because the coordinator became department chair and one because the coordinator went on leave).

The Miami Teaching Portfolio Project has been similar in many ways to the departmental instructional liaison approach (DeZure, 1996), with the Miami department Project coordinator playing the same role as the instructional liaison. Although the major difference appears to be the Miami focus on the teaching portfolio, many departmental activities in the Miami Project have included those on the instructional liaison list, because a portfolio approach to teaching raises broad teaching issues that are then discussed within the department.

\section{What Was Learned About the Department-Based Development Process}

One especially interesting outcome of the Teaching Portfolio Project is the great diversity in approaches across disciplines and in Project coordinators selected by the departments. For example, some department teams include graduate students, one team shares information via an e-mail network, some involve mentoring pairs (in one case, each pair developed a joint portfolio), some use grant money to reward those who complete portfolios, and one department developed a "group dialogical portfolio." The approach depended on the culture of the department, the discipline, and the style of the coordinator. Because of the flexibility built into the Project and encouraged by the Director, many development styles flourished.

Every year each Project coordinator prepares interim and final reports that address 15 questions about the Project (a summary is available from the author upon request). See Cox (1995a) for Project outcomes about teaching portfolios (what was learned, unanswered questions, advice for specific disciplines, etc.) and for results about and recommendations for department chairs. Several themes of interest to faculty developers have emerged from these reports.

\section{Off-Campus Consultants}

The coordinators had different views on the value and timing of 
involving off-campus consultants. For example, one coordinator wrote, "Hire an affordable, caring consultant who knows about portfolios (and knows your discipline). Having a professional facilitator come in at the beginning saves many hours of undirected, amateurish conversations with colleagues." On the other hand, another coordinator wrote, "Do your own learning and mentoring. This is especially beneficial if the group works together in small teams. This approach has many advantages, such as: learning to communicate with other learners, developing your own schedule, integrating effectively your work with other assessment activities conducted in your own classes, and learning from your own mistakes. Also, to us, the idea of bringing consultants sounded more mechanical than intellectual: do this and you will get a portfolio! We would rather start on our own and later, we may consult with others on a more intellectual level that attempts bringing the work to reflect on the dynamics and complexity of classroom teaching as well as the scholarship of teaching."

Currently, 7 of the 16 units that have participated in the Project have used off-campus consultants; none of the consultants has served more than one department, although some coordinators from other departments have attended sessions led by the visitor. So far only two units have used off-campus consultants during their second year, and although these were nationally known teacher scholars in the department's discipline, they were not teaching portfolio experts. One department team member commented that their consultant claimed to learn more than he contributed. Teaching portfolio experts outside the department's discipline have been involved only during the first year. None of the units has used consultants the third year. Table 2 summarizes the use of consultants.

\section{Grant Support Funding}

An essential part of the Project is the incentive and support that the $\$ 5,000$ grant funding provides to the department and the Project team. These grants have been used by the departments mainly in four ways: to fund off-campus consultants, to provide incentive dollars to cover some professional expenses for team members who complete portfolios, to purchase books about teaching portfolios for team mem- 
bers and the department library, and to cover the meal costs at departmental retreats or seminars. The most expensive item is an off-campus consultant, and in some cases departments have used their own funds to help cover the cost.

\begin{tabular}{|l|l|l|}
\hline \multicolumn{3}{|c|}{ TABLE 2 } \\
Use of Off-Campus Consultants \\
\hline & \multicolumn{1}{|c|}{$\begin{array}{c}\text { Experienced Teaching } \\
\text { Portfolio Consultant }\end{array}$} & \multicolumn{1}{|c|}{$\begin{array}{c}\text { Nationally Known } \\
\text { Teacher Scholar }\end{array}$} \\
\hline Not in the Discipline & $\begin{array}{l}\text { Art } \\
\text { Architecture } \\
\text { Geography* } \\
\text { Hamilton Campus } \\
\text { Educational Leadership }\end{array}$ & \\
\hline In the Discipline & $\begin{array}{l}\text { Geography* } \\
\text { History }\end{array}$ & $\begin{array}{l}\text { Geography"* } \\
\text { University Libraries }\end{array}$ \\
\hline *Used a team of two consultants working jointly with the department during the first year \\
\hline
\end{tabular}

\section{Release Time}

Although release time for the Project coordinator was suggested as a possible use for part of the department grant, only one of the departments elected to use funds this way (in contrast to the instructional liaison approach, in which each liaison receives release time).

Sixteen of the 22 coordinators who did not elect release time responded to a survey asking them to rank the reasons for their decision. Twelve indicated that being a project coordinator was part of their professional service, hence should not require release time (five ranked this the primary reason). Twelve also were uncomfortable with using funds for release time because their team members would not have this privilege (only one person ranked this first). Eleven indicated that grant funds were needed more for other Project costs (three ranked this first). Nine (two ranked first) did not choose release time because they thought the amount of their time devoted to the project would not justify release time; only two of these nine, looking back on the experience, wished that they had requested release time. Other reasons given were as follows: Five believed that release time 
would not fit into their department's culture, three considered release time unrealistic because they were codirecting the Project, and one coordinator's department chair would not permit it. Two coordinators were given professional support as a thank you.

\section{Formative vs. Summative}

The teaching portfolio concept was developed for better evaluation of teaching (Knapper, 1995), and an evaluation-of-teaching system "must provide rich, complex, formative, developmental, nonstandardized information....If nonstandardized information is to be valued, the traditional statistical evaluation approaches that exalt reliability and validity will not be enough" (Richlin \& Manning, 1996, p. 67). Richlin and Manning (1995) have developed a two-year process and curriculum for moving through formative to summative use of portfolios.

Yet, the units in the Miami Project have split evenly on whether their primary direction should be the development of portfolios for self- as well as department- improvement or for better evaluation of teaching. One coordinator wrote, "Consider this project as an extension to your own teaching (internal reward) and your striving to be an effective teacher. Do not worry yet about the impact of this project on your promotion and tenure (external reward) because it is beyond your direct control. However, everyone in this team believes that the internal reward will have eventually an excellent impact on the external one."

Half the departments report that the most important unanswered question about portfolios involves evaluation issues. To answer these questions, most coordinators report that their unit will need more time and experience. One coordinator wrote, "We agree that the only good reason to do the work involved in a portfolio is to use it for evaluation of teaching, but we have no clear idea of how that might happen. This ambiguity produces anxiety, or in the words of Duke Hunter Thompson, 'fear and loathing.'" For some departments, one negative outcome of the Project's flexible approach is the dissonance between a department's ambiguity about the summative use of portfolios and a department's inability (or paralysis) to engage in or complete a process 
to resolve the ambiguity (for example, defining effective teaching and agreeing on ways to measure it in a portfolio).

\section{Lack of Time}

Project coordinators cite the lack of time as by far the most significant barrier to the portfolio development process. Seven of the 16 units report that there is not enough time to meet, to do homework, and to develop portfolios. In some cases, developing portfolios and incorporating them into an evaluation-of-teaching system is not a high priority. One coordinator reported, "We did meet once a month, but it wasn't always easy to find a slot. . . When events of a pressing departmental nature came up....we were likely to get bumped." Another noted, "Faculty are really pressed for time; we have other competing reforms we are working on....We are addressing this by having a place for the teaching portfolio on the faculty meeting schedule....Time and energy are in short supply." In spite of these time constraints, only one coordinator so far has selected release time.

[S]ome professors decry the time and effort they put into constructing their portfolios when the work does not lead to their selection as award winners or to the promotions they anticipated. We believe this reaction occurs because of what we have not seen in evaluation projects using portfolios: a concurrent process to understand and express what constitutes excellent teaching and to develop a teaching evaluation system that reflects that understanding. (Richlin \& Manning, 1996, p. 66)

Most departments and faculty will not invest time in the portfolio development process until the prestige and rewards for such efforts are equivalent to those for discovery scholarship. Faculty and departments seeking this time find it part of a zero-sum game: the time must come from, instead of being added to, current commitments to teaching, research, and service. Teaching development programs at Miami University have tried to generate some time and reward via semester and summer teaching leaves, summer teaching fellowships, and course release time for individuals who are participating in the yearlong junior or senior faculty teaching development programs. Department-based teaching projects like this one must include financial or other significant rewards for the participating department. 


\section{Collegiality}

In their study of conditions within departments that support or inhibit faculty efforts to enhance undergraduate education, Massy, Wilger, and Colbeck (1994) found that exemplary departments had the following characteristics: "[A]n emphasis on teaching, frequent interaction, tolerance of differences, generational and workload equity, peer evaluation, and consensus decision-making.... a pattern recognized widely in higher education: collegiality"'(p. 18). Although there may have been other vestiges of collegiality in a department, such as discussing research, course offerings, or promotion and tenure, these constituted a "hollowed" collegiality that did not contribute to improving undergraduate education.

The units that applied to participate in the Miami Project had volunteers who formed teams that operated in a collegial manner. One coordinator wrote, "We are a very eclectic group of individuals with varied needs, so we have tried to keep the structure of the project as open as possible. We met once a month....to share course and portfolio materials.....and we always had food and drink at these meetings as a way of helping to create a relaxed atmosphere."

However, although the team may have been a collegial group, sometimes it was an oasis within the department. One coordinator lamented in a final report, "While the group is open to all and all are encouraged to participate, most in the department do not, so many in the group feel that our activities are not significant." The monthly meetings of the Project coordinators provided a support group for those with such frustrations. It has been important to encourage collegiality at two levels of the Project: on the department team and in the coordinators group.

Finally, the degree of collegiality of the team contributes to the openness, support, and trust necessary when creating portfolios may involve sharing one's weaknesses. One coordinator wrote, "Dealing with teaching is truly like peeping in someone's window...some don't care, some care but want selective views taken, and others are very hesitant." Richlin (1995) recommends that faculty start by working privately on course portfolios before taking part in a public, community project to develop the broader-based teaching portfolio. 


\section{Directive or Nondirective?}

By design the Project is nondirective in that it gives departments the flexibility to implement their own portfolio development process. The Project coordinators have split evenly in taking directive or nondirective approaches. On the directive side, a few departments have used grant money to support the travel of team members, provided they agreed to develop a portfolio by the end of the year; this approach generated 12 portfolios in one department. The three departments that had low productivity and became inactive in the Project after a year did not tie disbursement of funds to product or outcomes. However, some coordinators say that the product/reward approach would discourage them; they prefer a voluntary or intellectual approach.

Perhaps a balance between the two approaches is best. One coordinator organized and coordinated an extensive sequence of seminars for his unit; the team even started before classes began. However, he reflected at the end of the year:

Stay flexible!!! Nothing happens as fast as you think it will. Be willing to pause, take valuable side trips dictated by the ebb and flow of the group, don't push too hard, and listen a lot more than you talk. Good things will happen, but it takes time and will not follow the road map drawn on day one. Also, be sure everyone is having fun and enjoying the process. Do fun things. Eat well. Build a culture of trust and mutual respect. Learn from the diversity and creativity of the individuals in the group.

Two departments have successfully completed the Project, at least to the point that they now require portfolios from all faculty for evaluation. For these two departments, one of the Project coordinators is directive, the other is not. Both used their styles successfully to accomplish the objectives of the Project.

\section{Sharing Progress With the Campus and Beyond}

Each spring semester the Miami coordinators have presented a campus-wide colloquium on the teaching portfolio. The first year, the objectives of the one-hour session were to present a brief overview and flavor of teaching portfolios, to explain the purpose of the Project 
on campus, to report on what the participating departments had learned to date, and to answer questions. Of those returning session evaluations, 18 indicated they would try portfolios, 7 said maybe, and 3 said no. The second year, the colloquium had the same objectives but also included insights from a panel of five experienced coordinators: They presented key points about their portfolio development and were available afterward to share their portfolios and consult with faculty. The session evaluations this time indicated that 13 would try a portfolio, 5 might do so, and only 1 would not. The third year's campus presentation featured a two-hour workshop, led in small groups by experienced coordinators and team members, on plans and first steps about constructing course or comprehensive portfolios (Cox, 1996).

At the 1994 Lilly Conference, six sessions on the portfolio were volunteered and presented, including a panel of the 13 department representatives from the Miami Project. At the 1995 Lilly Conference, only two sessions about teaching portfolios were volunteered from the national audience; for 1996 , none has been submitted so far. It would be interesting to learn why presentations about the teaching portfolio have declined from a high of 9 in 1993: Perhaps they are no longer an innovation or curiosity; perhaps their use has been either mastered or rejected as difficult, impractical, or ineffective. It is time to investigate the extent and purpose of teaching portfolio use.

\section{Recommendations for Faculty Developers}

For campuses considering a department-based approach to teaching development, to changing departmental teaching cultures, or to initiating dialogue about teaching within departments, the following recommendations based on the results of Miami's Teaching Portfolio Project might be helpful:

1. Make the initiative faculty-generated $\longrightarrow$ a grassroots effort-with administrative endorsement. Back this with proactive involvement of a provost or dean so the effort receives a higher priority in the departments.

2. Keep department participation in the project voluntary, because mandatory participation may cause resentment and resistance.

3. Reward and financially support departments that participate. 
4. Use a project coordinator and a department team approach to defuse the "chosen expert" or "prophet in one's own land" negative effect that one designated faculty member might face in the department.

5. Don't encourage or require generic, across-the-discipline approaches.

6. Provide sufficient flexibility and time for departments to design their own approach. Let them investigate and decide whether to use off-campus consultants, release time, a formative or summative approach, beginning with course or comprehensive portfolios, and so on.

7. Let the project coordinator and team investigate and then choose a portfolio development process that is directive or nondirective, product-oriented or voluntary.

8. Select project coordinators who are respected in their departments, enthusiastic about teaching, and former participants in campus-wide teaching programs.

9. Secure strong support from the department chair, but allow flexibility in the chair's role in the project. The department's culture and level of collegiality will dictate the chair's role.

10. Provide emotional support at two levels: for the team within the department and for the coordinators of these teams across campus.

11. Have the department project coordinators meet monthly to share experiences, establish networks across departments, and address issues of interest to the group.

12. Accept the time inefficiency of a department-based approach. Some departments may seem to "reinvent the wheel," but in most cases they will create an innovative design that fits and highlights the culture of the department and discipline. Also, faculty are more excited and committed when, after investigating the literature, they can be creative in combining the scholarship of discovery, application, and teaching.

13. Accept the economic inefficiency of a department-based approach. A department may bring in a national expert who does not have time to consult with other departments or the entire campus. A department values special consultation and attention tailored to 
its culture and discipline. Other project coordinators should be invited to join any department's public presentations.

14. Allow at least three years for completion or expansion of a department-based project.

15. Provide incentives for continued participation each year. Some departments in the Miami Project have been participating at least three years and still need more time. However, the entire amount of the $\$ 5,000$ grant is given to and may be used by a department in its first year of participation. It is helpful to provide departments an opportunity to apply for additional funds.

16. After the first year or two of a departments' participation in the project, be prepared for some departments to "stop out" when undergoing chair searches, moving to temporary quarters, etc. $\mathrm{Be}$ patient and encourage departments undergoing transition to renew their efforts.

17. When a project coordinator must step down before the project is completed, be alert for a change in the quality of leadership and department participation. There must be frank and open discussion about project expectations between a new coordinator, the department chair, and the central faculty development person overseeing the project.

18. Share the progress of departments with the campus at seminars presented by the department project coordinators.

19. If a teaching development effort is successful (whether central or department-based), continue it long-term to achieve a broad impact on the campus and to generate faculty leaders for other department-based projects.

20. Do not rely exclusively on department-based teaching development approaches. Continue other university-wide approaches because some departments will not participate in the department-based project; some faculty within a department may not feel safe to reveal weaknesses to colleagues in the department; and innovative teaching methods may not initially be known or of interest to a department.

The application of these recommendations, of course, must take into account the culture of the particular campus. 


\section{Conclusions}

\section{Impact of the Project}

After almost three years, every unit participating in the Project reports that all or a core group of department faculty have enjoyed and learned from having an active dialogue about teaching - in most cases the first such dialogue about teaching in years. The instructional liaison initiative at Eastern Michigan University reports the same outcome (DeZure, 1996).

In two of the 16 participating units at Miami, the Project has generated use of teaching portfolios by all faculty for formative and summative evaluation. In one of these departments a very good evaluation-of-teaching system was already being put into place when the project began. The Project enabled that department to fine tune its system by consulting a nationally known expert in the evaluation of teaching. Only three of the 16 units are inactive, with the others in various stages of portfolio or evaluation development. The coordinators continue to meet monthly, including holding seminars on various teaching topics such as ethical dilemmas in teaching.

Although only two of the 16 units participating in the Teaching Portfolio Project at Miami University have embraced teaching portfolios as a process for developing and evaluating teaching for all faculty, some of the other participating departments now require or encourage portfolios for promotion and tenure. Individual faculty have reported that developing a portfolio is a valuable developmental experience that contributes to more effective teaching and student learning, although the time commitment is extensive. In participating departments, the Project has initiated or renewed departmental interest in and discussion about teaching, and the campus climate for investigating and broadening the evaluation of teaching is now favorable.

In 1995 a benefactor established a new teaching award at Miami to recognize excellence in undergraduate teaching that is creative and innovative, engages students with other learners, causes students to think critically, and promotes understanding of contexts. The ninemember award selection committee included both a department team member and a coordinator from the Project; they helped guide the 
design of the selection process to require teaching portfolios from the award finalists. The portfolio evaluation process has worked extremely well, providing clear evidence that the award criteria are met, while honoring the diversity of individual teaching approaches. One of the Project coordinators received the first award.

The Portfolio Project has also contributed to a broadening of the evaluation-of-teaching policy of the University. In 1995 the University Senate passed a resolution requiring that departments develop teaching evaluation plans "that reflect the complexity of the teaching/learning process by including multiple sources of evaluation data, including both qualitative and quantitative assessment methods... In addition to end-of-semester student evaluations, summative and formative activities could include, but are not limited to, ongoing classroom assessment, peer evaluations,... teaching (faculty) portfolios, classroom materials...."

Another impact of the Project has been on the development of graduate teaching assistants. Some departments include graduate students as Project team members; one coordinator wrote, "In a recent external review...the reviewing team verbally cited the portfolio project as being unique, and uniquely effective among...departments with which they were familiar in contributing to the training of graduate students as teachers."

Some concerns arising from the departmental instructional liaison approach (DeZure, 1996) have not surfaced in the Miami approach, because most departmental colleagues have been willing to discuss problems with the Project team as opposed to a single liaison. Also, departments have not perceived the Project as an administrative intervention to remedy some department shortcoming, because participation is voluntary and the Project is faculty-based.

\section{Next Steps: Broadening the Focus}

Several initiatives can follow from a department-based teaching portfolio project; some of the departments in the Miami Project are moving in the following directions:

One is to investigate other types of portfolios and to incorporate them into a scheme focused on department learning. In concert with 
the teaching portfolio, there are several other varieties of portfolios: the course portfolio, which describes a single course (Cerbin, 1994); the professional portfolio, which relates one's teaching, research, and service (Froh, Gray, \& Lambert, 1993); and the student portfolio, which causes students to reflect upon, analyze, and provide evidence of learning in a course or across the years in their major (Cox, 1995c; Murnane, 1993). All these portfolios can fit together in various ways to enhance student, instructor, and department learning (Cox, 1995a). One department in the Miami Project plans to begin this initiative next year.

A second initiative is to broaden the teaching portfolio project into one aimed at improving departmental evaluation-of-teaching systems. In the third year, the name of the Project was changed to the Evaluation of Teaching Project, and for the fourth year, it will be called the Improvement of Evaluation of Teaching Systems Project. In some departments, portfolios may be part of this.

A third initiative is to encourage departments to focus on their teaching cultures (Walvoord, 1994). Wergin (1994), looking for universities that encourage departments to become self-directed collectives, found none. In a study of five "well respected universities that seem to be inching toward cultures of greater collective responsibility" (p. viii), he identified four different challenges: developing departments as teams, balancing group and individual interests, redefining evaluation, and evaluating and rewarding group efforts. One Miami Project coordinator wrote in his final report about his department's move toward collective responsibility:

Initially we thought of this use of portfolios as something the faculty members would do by themselves, or, at most, with one other person ... What happened, however, was that our discussions resulted in developing the idea of a "group dialogical portfolio." This term is only a metaphor, really, for the "portfolio" in question would not take a physical form (e.g., be a collection of material on paper in a loose-leaf binder). Rather, the idea is for the evaluation of teaching to go on by having a small group of people reflect on and discuss material presented by someone about their teaching. . . . This idea emerged from our growing recognition that what we team members valued most from our meetings was the discussion we had about teaching. ... In addition, it 
was a way of increasing the "collective responsibility for teaching" in the department that we had set as one of the team's goals.

In conclusion, faculty developers also must be department developers. The Miami Project illustrates that flexible, funded, departmentbased teaching development projects provide one way to enable department learning while honoring the diversity of departments, disciplines, and project leaders. And a department-based teaching portfolio project provides a broad, scholarly approach to enhancing the teaching culture of any department that is willing to try.

\section{References}

Anderson, E. (1993). Campus use of the teaching portfolio: Twenty-five profiles. Washington, DC: American Association for Higher Education, The Teaching Initiative.

Boice, R. (1985). Differences in arranging faculty development through deans and chairs. Research in Higher Education, 23(3), 245-255.

Cerbin, W. (1994). The course portfolio as a tool for continuous improvement of teaching and learning. Journal on Excellence in College Teaching, 5(1), 95-105.

Cox, M. D. (1994). Reclaiming teaching excellence: Miami University's Teaching Scholars Program. To Improve the Academy, 13, 79-96.

Cox, M. D. (1995a). A department-based approach to developing teaching portfolios: Perspectives for faculty and department chairs. Journal on Excellence in College Teaching, 6(1), 117-143.

Cox, M. D. (1995b). The development of new and junior faculty. In W. A. Wright (Ed.), Teaching improvement practices: Successful strategies for higher education (pp. 283-310). Bolton, MA: Anker.

Cox, M. D. (1995c, March). Using student portfolios to enhance learning. Paper presented at the Lilly Conference on College Teaching-West, Lake Arrowhead, CA.

Cox, M. D. (1996). Preparing a teaching portfolio: A working session. Oxford, OH: Miami. University, Office for the Advancement of Scholarship and Teaching.

Cox, M. D., \& Blaisdell, M. (1995, October). Teaching development for senior faculty: Searching for fresh solutions in a salty sea. Paper presented at the national conference of the Professional and Organizational Development Network in Higher Education, North Falmouth, MA.

Davis, J. T., \& Swift, L. J. (1995). Teaching portfolios at a research university. Journal on Excellence in College Teaching, 6(1), 101-115.

DeZure, D. (1996, February). Closer to the disciplines: A model for improving teaching within departments. AAHE Bulletin, 48(6), 9-12.

Eison, J. (1994, November). Conducting teaching portfolio workshops: A tale of three audiences. Paper presented at the 14th Annual Lilly Conference on College Teaching, Oxford, $\mathrm{OH}$. 
Froh, R. C., Gray, P. J., \& Lambert, L. M. (1993). Representing faculty work: The professional portfolio. In R. M. Diamond \& B. E. Adam (Eds.), New directions for higher education: No. 81. Recognizing faculty work: Reward systems for the year 2000 (pp. 97-110). San Francisco: Jossey-Bass.

Hilsen, L., \& Rutherford, L. (1991). Front line faculty development: Chairs constructively critiquing colleagues in the classroom. To Improve the Academy, 10, 251-269.

Hutchings, P. (1993, May). Introducing faculty portfolios: Early lessons from CUNY York College. AAHE Bulletin, 45(9), 14-17.

Hutchings, P. (1996). Making teaching community property: A menu for peer collaboration and peer review. Washington, DC: American Association for Higher Education, The Teaching Initiative.

Knapper, C. K. (1995). The origins of teaching portfolios. Journal on Excellence in College Teaching, 6(1), 45-56.

Kurfiss, J., \& Boice, R. (1990). Current and desired faculty development practices among POD members. To Improve the Academy, 9, 73-82.

Lunde, J. P., \& Barrett, L. A. (1996). Decentralized/departmental reward systems. In M. D. Svinicki \& R. J. Menges (Eds.), New directions for teaching and learning: No. 65. Honoring exemplary teaching (pp. 93-98). San Francisco: Jossey-Bass.

Massy, W. F., Wilger, A. K., \& Colbeck, C. (1994, July/August). Overcoming "hollowed" collegiality: Departmental cultures and teaching quality. Change, 26(4), 11-20.

Murnane, Y. (1993). Good grading: Student portfolios-a primer. The National Teaching and Learning Forum, 3(2), $1-4$.

Murray, J. P. (1995). The teaching portfolio: A tool for department chairpersons to create a climate for teaching excellence. Innovative Higher Education, 19(3), 163-175.

Richlin, L. (1995). A different view on developing teaching portfolios: Ensuring safety while honoring practice. Journal on Excellence in College Teaching, 6(1), 161-178.

Richlin, L., \& Manning, B. (1995). Improving a college/university teaching evaluation system: A comprehensive, developmental curriculum for faculty and administrators. Pittsburgh, PA: Alliance.

Richlin, L., \& Manning, B. (1996). Using portfolios to document teaching excellence. In M. D. Svinicki \& R. J. Menges (Eds.), New directions for teaching and learning: No. 65. Honoring exemplary teaching (pp. 65-70). San Francisco: Jossey-Bass.

Ross, D. D., Barfield, C. S., Campbell, E. S., Capaldi, E. D., \& Lombardi, J. V. (1995). Teaching as a priority: A promising program at the University of South Florida. College Teaching, 43(4), 134-139.

Seldin, P., \& Associates. (1993). Successful use of teaching portfolios. Bolton, MA: Anker.

Sorcinelli, M. D., \& Aitken, N. D. (1995). Improving teaching: Academic leaders and faculty developers as partners. In W. A. Wright (Ed.), Teaching improvement practices: Successful strategies for higher education (pp. 311-324). Bolton, MA: Anker.

Walvoord, B. E. (1994, November). Creating a teaching culture in your department. Paper presented at the 14th Annual Lilly Conference on College Teaching, Oxford, $\mathrm{OH}$.

Wergin, J. F. (1994). The collaborative department: How five campuses are inching toward 
cultures of collective responsibility. Washington, DC: American Association for Higher Education, Forum on Faculty Roles and Rewards.

Wilhite, M. S. (1990). Department heads as faculty developers: Six case studies. To Improve the Academy, 9, 111-121.

Wright, W. A., \& O'Neil, M. C. (1995). Teaching improvement practices: International perspectives. In W. A. Wright (Ed.), Teaching improvement practices: Successful strategies for higher education (pp. 1-57). Bolton, MA: Anker.

\author{
Contact: \\ Milton D. Cox \\ Miami University \\ Teaching Effectiveness Programs \\ 106 Roudebush Hall \\ Oxford, OH 45056 \\ (513) 529-6648 Phone \\ (513) 529-3762 FAX \\ cox_milt@msmail.muohio.edu
}

Milton D. Cox has been the University Director for Teaching Effectiveness Programs at Miami University for twelve years. He is founder and director of The Lilly Conference On College Teaching, co-founder and editor-in-chief of the Journal on Excellence on College Teaching, and directs the 1994 Hesburgh award-winning Teaching Scholars Program. He teaches mathematics and has served as chair of the Ohio Section of the Mathematical Association of America and as president of Pi Mu Epsilon, the national mathematics honorary society, which awarded him the C.C. MacDuffee Award for meritorious service.

The author thanks the following Miami faculty who have served as coordinators for their departments and/or presented their portfolios at campus-wide colloquia: David Belka, Muriel Blaisdell, Claire Boge, Mary Kupiec Cayton, Connie Collier, Don Daiker, Dan Duricy, Thomas Dutton, Osama Ettouney, Peg Faimon, Barbara Galik, Jack Gifford, Jim Hamill, Mary Sue Johns, Stacey Kimmel, Allison McCormack, William McKenna, Brenda Mitchell, Jerry Morris, James Rubenstein, Lee Sanders, Gary Shulman, Charles Skipper, Shannon Sullivan, and Bill Wortman. 